\title{
ELECTROCHEMICALLY ASSISTED ADSORPTION/DESORPTION OF BENTAZONE ON ACTIVATED CARBON CLOTH
}

C.O. Ania ${ }^{\mathrm{a}}$, F. Béguin

CRMD, CNRS-University, 1B rue de la Férollerie, 45071 Orléans, France

a Current address: Instituto Nacional del Carbón, CSIC, Apdo. 73, 33080 Oviedo, Spain (conchi@incar.csic.es)

\begin{abstract}
This paper investigates the application of an electrochemical technique for the removal of a common herbicide, bentazone, from water streams using a carbon-based electrode. Activated carbon cloth with high surface area and narrow micropores was used as electrode. For a better understanding of the process, adsorption was investigated under both open circuit and controlled polarization conditions, the latter in anodic and cathodic directions. It was found that anodic polarization enhances the kinetics of adsorption of the herbicide on the carbon cloth, the extent of which is strongly related to the applied current value. At converse, cathodic polarization induces the reversible desorption of the compound. Moreover, in-situ UV spectra recording on the solution did not show any structural change of the herbicide upon polarization, demonstrating the reversibility of the process for the regeneration of the adsorbent and the recovery of the compound. Based on these experiments, a mechanism is proposed to interpret the reversible sorption of bentazone under application of an electrochemical polarization.
\end{abstract}

Keywords: electrosorption, electrodesorption, activated carbon cloth, pesticides, liquid phase adsorption 


\section{Introduction}

Dependence on chemical pesticides and fertilizers is one of the most adverse aspects of intensive agriculture and industrial activities, with negative environmental, health and economic aspects. World used amount of pesticides exceeded 2 million tons in 2001, herbicides accounting for the largest fraction of the total use in the European Union (EU) (European Communities, 2005; EPA, 2004). Their repetitive utilization to maintain health crops has lead to an increase of their level in wastewater from industrial and human activities. Moreover, pesticides are considered by the EU as priority pollutants (Directive 2000/60/EC) as they are highly noxious, long-term persistent and highly mobile throughout the environment and most of them also present carcinogenic properties. Although environmental concerns on pesticides use in developing countries were raised thirty years ago, hazardous pesticides are still used with little or no protection. Therefore, the issue of their removal has become a field of growing interest.

Particularly, the use of bentazone, a post-emergence herbicide, has become very popular for the control of broad-leaved weeds and crops since 2003 after the ban of atrazine in the EU. In association, the herbicides alachlor and bentazone can be substituted for atrazine to provide the same spectrum of action on weeds in cereals grains crops (mainly maize and rice), resulting in new environmental risks (Dousset et al., 2004). Moreover, bentazone has a relatively high mobility in water.

Faced with an increasing contamination of natural waters by pesticides, adsorption on activated carbon has become widely used in water treatment plants (Bandosz, 2006), due to its high depuration efficiency. Thus, the design of an adsorption treatment has to be based on i) the transient force which drives the targeted pollutant from the aqueous phase towards the adsorption sites in the adsorbent and ii) the technological and economical feasibility of regeneration of the spent adsorbent.

In this connection, electrosorptive techniques employing high surface area electrodes of nano-textured carbons have been recently investigated as a potential technology for removing toxic pollutants from 
aqueous solutions. The working principle of electrosorption is based on imposing an external electric field in order to force charged species such as ions to move toward oppositely charged electrodes. This technology offers several advantages such as the reversibility, which enables the possibility of the regeneration of the exhausted activated carbon. So far, electrochemical techniques have been successfully applied for the removal of ions (Alfarra et al., 2002; Ying et al., 2002; Afkhami and Conway, 2002) and a few organic molecules (Niu and Conway, 2002a-c; Niu and Conway, 2004, 2003; Ayranci and Conway, 2001; Han et al., 2006a, b), or for the regeneration of adsorbents (Brown et al, 2004; Zhou and Lei, 2006). In contrast, scarce works report their use for the electroadsorption or the electrodesorption of pesticides or more complicated polycyclic aromatic compounds (Niu and Conway, 2002a-c; Niu and Conway, 2003; Ania and Béguin, 2007).

The main objective of this research is to explore the application of an electrochemical technique for the adsorption and desorption of bentazone, using an activated carbon cloth as electrode. For the sake of comparison, the adsorption process was also investigated under open-circuit conditions (i.e., without polarization). Special attention was paid to the different factors (heterogeneity of the carbon surface, solution $\mathrm{pH}$, current) that affect the complex process of adsorption and electrosorption from solutions. So far, scarce results have been reported on the use of electrochemical techniques for the adsorption of herbicides on carbon materials (Ania and Béguin, 2007).

\section{Experimental}

\section{Materials}

A commercial activated carbon cloth - $A X$-, supplied by ACTITEX (France) was used. The sample was washed with distilled water at $60{ }^{\circ} \mathrm{C}$ during one week, dried at $80{ }^{\circ} \mathrm{C}$ overnight and stored in a dessicator until use. Bentazone [3-Isopropyl-1H-2,1,3-benzothiadiazin-4(3H)-one-2, 2-dioxide]- with the highest purity specification was obtained from Aldrich. 


\section{Textural and chemical characterization of the carbon cloths}

Nanotexture of the carbon cloths was characterized by $\mathrm{N}_{2}$ adsorption at $-196{ }^{\circ} \mathrm{C}$ (Autosorb-1, Quantachrome). Before the experiments, the samples were outgassed under vacuum at $120{ }^{\circ} \mathrm{C}$ overnight. The isotherms were used to calculate the specific surface area, $\mathrm{S}_{\mathrm{BET}}$, total pore volume, $\mathrm{V}_{\mathrm{T}}$, and pore size distribution using the density functional theory (DFT). Additionally, the distribution of pores smaller than $0.7 \mathrm{~nm}$ (narrow micropores) was assessed from $\mathrm{CO}_{2}$ adsorption isotherms at $0{ }^{\circ} \mathrm{C}$ with the DR formulism. The materials were further characterized by the determination of the point of zero charge $\left(\mathrm{pH}_{\mathrm{pzC}}\right)$ by mass-titration as described elsewhere (Noh and Schwarz, 1989).

Kinetics of adsorption / electrosorption/electrodesorption

Kinetics of adsorption/electrosorption was determined in $20 \mathrm{~mL}$ of bentazone aqueous solution with a fixed mass $(11 \pm 0.5 \mathrm{mg})$ of carbon cloth attached to a gold disk acting as current collector for the electrosorption experiments. In the latter case, due to the low electrical conductivity of the pesticide solutions, 0.01 mol. $\mathrm{L}^{-1} \mathrm{Na}_{2} \mathrm{SO}_{4}$ was used as inert supporting electrolyte ( $\mathrm{pH}$ of the resulting solution ca. 5-6). A platinum grid served as auxiliary electrode, and $\mathrm{Hg} / \mathrm{Hg}_{2} \mathrm{SO}_{4}$ as reference electrode. Small samples of the solution $(2 \mathrm{~mL})$ were taken out at predetermined time intervals to measure the $\mathrm{pH}$ evolution and the concentration of pollutant during sorption, using a UV spectrometer (Uvikon Xs, Bio-TEk Instruments) at the corresponding maximum absorption wavelength, depending on the solution $\mathrm{pH}$. The extracted samples were re-introduced in the cell in order to avoid changes in the total volume of solution. This procedure enabled to investigate the kinetics of adsorption under both opencircuit (OC) and polarization at different current densities of $+1,+2$ and $+5 \mathrm{~mA}$ (i.e., galvanostatic mode). The adsorption rate constants were determined from the first-order adsorption kinetics equation:

$$
\log \left(q_{e}-q\right)=\log q_{e}-\frac{K_{a d s} t}{2.303}
$$


where $K_{\text {ads }}\left(\mathrm{min}^{-1}\right)$ is the adsorption rate constant and $q_{e}$ and $q$ are the amounts of bentazone adsorbed $\left(\mathrm{mg} \mathrm{g}^{-1}\right)$ at equilibrium and time $\mathrm{t}(\mathrm{min})$, respectively.

The possibility of regenerating the exhausted carbon cloth by means of electrochemical techniques was also explored by the reversal of polarization (i.e., cathodic). The carbon cloth was previously exhausted at open-circuit conditions (OC). Once loaded, the sample is polarized applying a cathodic current (i.e., $-5 \mathrm{~mA}$ ) for 3 hours, to provoke the pollutant desorption, using the same electrochemical cell aforementioned described. After desorption, the carbon cloth sample was allowed to rest in the same cell until saturation was again attained, before starting a new desorption cycle.

\section{RESULTS AND DISCUSSION}

\subsection{Characterization of the carbon cloths}

Detailed nanotextural characteristics of the as-received cloth are presented in Table 1 . The analysis of the PSD, combining the information of $\mathrm{N}_{2}$ and $\mathrm{CO}_{2}$ adsorption isotherms, indicates that the pore volume determined by $\mathrm{CO}_{2}$ data is larger than the corresponding volume of micropores "seen" by $\mathrm{N}_{2}$, indicating that the microporosity of the carbon cloth is mainly composed of pores narrower than $0.7 \mathrm{~nm}$. Moreover, the mesopore volume accounts generally for less than $10 \%$ of the overall porosity. In order to explore the possible changes in texture and surface functionality of the carbon cloth upon electrochemical treatment, a blank experiment was carried out by exposing the cloth to both anodic and cathodic polarization in the absence of the pollutant. For these experiments, the carbon cloth was initially polarized between -600 and $+200 \mathrm{mV}$ vs. $\mathrm{Hg} / \mathrm{Hg}_{2} \mathrm{SO}_{4}$; then it was progressively submitted to more negative ( $A X$ cath) or to more positive ( $A X$ anod) cut-off potentials, down to $-1200 \mathrm{mV}$ and up to $+600 \mathrm{mV}$, respectively. It is observed that the nanotexture of the carbon cloth remains almost unaltered after cathodic polarization treatment (Table 1); at converse, surface area, micropore and 
mesopore volumes slightly (ca. $8 \%$ ) decreased after anodic polarization. At the same time, the $\mathrm{pH}$ PzC decreases of 2 units.

When the carbon cloth is exposed to polarization between -600 and $+200 \mathrm{mV}$ vs. $\mathrm{Hg} / \mathrm{Hg}_{2} \mathrm{SO}_{4}$, a pure capacitive behaviour occurs (reversible charge/discharge of the double layer), which is confirmed by the rectangular shape of the voltammogram (Figure 1). At potentials below $-600 \mathrm{mV}$, a fast current leap related with water reduction and formation of nascent hydrogen is observed, along with an increase of anodic current attributed to the reversible electrochemical oxidation of adsorbed hydrogen (Jurewick, 2004). This effect is more pronounced as the cut-off potential decreases, due to an increasing kinetics of hydrogen production. It is important to remark that the carbon cloth has a reversible response; after applying negative potential values (ca. $-1200 \mathrm{mV}$ ), the voltammogram between -600 and $+200 \mathrm{mV}$ superimposes with the initial one. This is reasonable, taking into account that i) anodic polarization of the cloth was restricted up to $+200 \mathrm{mV}$ and ii) $\mathrm{H}_{2}$ and $\mathrm{OH}^{-}$are liberated at the working electrode upon cathodic polarization according to:

$2 \mathrm{H}_{2} \mathrm{O}+2 \mathrm{e}^{-} \rightarrow \mathrm{H}_{2}+2 \mathrm{OH}^{-}$

On the contrary, anodic polarization ( $\mathrm{AX}$ anod) at potentials higher than $+200 \mathrm{mV}$ vs. $\mathrm{Hg} / \mathrm{Hg}_{2} \mathrm{SO}_{4}$ causes a slight oxidation of the carbon cloth (Kinoshita, 1988), which is confirmed by the appearance of a reversible hump in the voltammogram, due to redox transfer reactions involving the oxygencontaining functionalities created in the carbon matrix (Figure 1). The position of the cathodic and anodic peaks confirms the existence of the quinone/hydroquinone pair (reduction potential close to $-0.15 \mathrm{~V}$ vs. $\mathrm{Hg} / \mathrm{Hg}_{2} \mathrm{SO}_{4}$ for carbons (Kinoshita, 1988) in various environments. Other groups of acidic nature are also created, as inferred by the decrease in the $\mathrm{pH}_{\mathrm{PZC}}$ of the resulting cloth (Table 1).

In sum, neither porosity nor surface functionality is altered by negative polarization of the carbon cloth; positive polarization at potentials higher than $+200 \mathrm{mV}$ vs. $\mathrm{Hg} / \mathrm{Hg}_{2} \mathrm{SO}_{4}$ provokes surface oxidation and minor nanotextural changes. This will be important for understanding the changes 
induced in the removal of bentazone during polarization (see discussion below), as they should be attributed to the presence of charges on the carbon surface, rather than to nanotextural changes.

In order to investigate the role of porosity, the nanotextural characteristics of the cloth after bentazone adsorption under polarization were also investigated (Table 1). As expected, the surface area and pore volume of the loaded sample decrease significantly. The fall is particularly important in the volume of micropores (evaluated by both $\mathrm{N}_{2}$ and $\mathrm{CO}_{2}$ adsorption), suggesting that adsorption takes place preferentially in the microporosity of the carbon cloth.

\section{2. $\quad$ Adsorption of bentazone under anodic polarization}

Initially, the electrochemical stability of the pesticide was investigated to ensure that bentazone is not oxidized or reduced during the electrosorption process. Cyclic voltammograms of the aqueous $0.01 \mathrm{~mol} \mathrm{~L}^{-1} \mathrm{Na}_{2} \mathrm{SO}_{4}$ solution, with and without the targeted pollutant, were recorded at a scan rate of $20 \mathrm{mV} \mathrm{s}^{-1}$ in the potential range between - 1000 and $+1250 \mathrm{mV} v \mathrm{~s}$. $\mathrm{Hg} / \mathrm{Hg}_{2} \mathrm{SO}_{4}$, using the gold disk as working electrode and platinum as counter electrode. No differences were found in the voltammograms when the herbicide is present in the solution; this was confirmed by UV absorption spectroscopy, which indicated that the bentazone spectra remain unchanged in this potential range.

When anodic (positive) polarization is applied to the carbon cloth at constant current (galvanostatic technique), the working electrode potential increases promptly and reaches a value that enables the electrolyte oxidation according to:

$$
2 \mathrm{H}_{2} \mathrm{O} \rightarrow \mathrm{O}_{2}+4 \mathrm{H}^{+}+4 \mathrm{e}^{-}
$$

(according to the Nernst equation, the equilibrium potential at the $\mathrm{pH}$ of the electrolytic solution (6.5) is $\mathrm{E}=+0.84 \mathrm{~V}$ vs $\mathrm{NHE} ;+0.15 \mathrm{~V}$ vs $\mathrm{Hg} / \mathrm{Hg}_{2} \mathrm{SO}_{4}$ )

At the same time, the passage of charge gives rise to a slight $\mathrm{pH}$ increase in the cell (up to one unit increase). This is linked to the faradaic production of $\mathrm{OH}^{-}$ions at the counter electrode during polarization, according to: 
Although in a non-separated cell the $\mathrm{OH}^{-}$ions created should be neutralized by the $\mathrm{H}^{+}$liberated at the working electrode, in this case the $\mathrm{pH}$ balance does not apply because the anodic process includes the non-faradaic charging (electrical double layer) of the high surface area carbon cloth. This behavior has also been reported for the electrosorption of azine-type pollutants (Niu and Conway, 2002a). Simultaneous trapping of protons in the micropores of the carbon cloth is another effect which could explain the $\mathrm{pH}$ increase in the cell. Although the increase is small, this might appreciably affect the efficiency of the electroadsorptive removal of the pollutant.

Regarding the bentazone uptake, anodic polarization caused an enhancement in the adsorption rate (Figure 2), being more significant with increasing the anodic current from $+1 \mathrm{~mA}$ to $+5 \mathrm{~mA}$. This was corroborated by the parameters of first-order kinetics (Table 2) calculated for the different anodic conditions. Given that the porosity of the carbon cloth is only slightly affected after anodic polarization as aforementioned, this enhancement in the adsorption rate should be attributed to the fact that the charge of the carbon surface and/or ionization of the adsorbate are being altered.

It should be stressed that bentazone is a weak acid with a $\mathrm{pK}_{\mathrm{a}}$ of 3.3; thus, at the $\mathrm{pH}$ of the supporting electrolyte $(\mathrm{pH} \sim 6.5)$ the anionic form is predominant in the solution, accounting for $98 \%$. By contrast, the neutral molecule is the main structure in solution at acidic $\mathrm{pH}$, representing ca. 95 mol \% at $\mathrm{pH}=2$. Taking this into account, we believe that the generation of protons at the working electrode could be the key factor in the electroadsorption, as it is responsible for the local $\mathrm{pH}$ decrease and it causes the protonation of the anionic bentazone form (predominant in the supporting electrolyte solution, as stated above) to the neutral form. According to previous studies about the role of $\mathrm{pH}$ on the mechanism of bentazone adsorption in open-circuit conditions (Ania and Béguin, 2007), bentazone is preferentially adsorbed in a molecular form. Therefore, bentazone uptake enhancement upon anodic polarization is a consequence of the local $\mathrm{pH}$ decrease that occurs in the electrode during polarization. 
Similar results, pointing out the $\mathrm{pH}$-dependence of bentazone adsorption at open-circuit conditions on soils and clays have been reported (Boivin et al., 2005; Ayranci and Hoda, 2004).

Concerning the mechanism of electrosorption, several factors should be considered. Because of the $\pi$ system interaction, it is expected that solute molecules are adsorbed with their aromatic ring adjacent to the cloth surface to maximize the dispersive interactions (Coughlin and Ezra, 1968). Such orientation has been reported to be favoured in most organic aromatics at small coverage conditions. In this flat position, induced dipole-charge interactions might take place easily between the carbon surface and the $\pi$-electrons. This is expected since the charge-density of the electrode surface changes upon polarization. As a consequence, this process promotes dipole-charge interactions and it is able to govern both the rates and extents of adsorption (Niu and Conway, 2004; Damaskin et al. 1971). A similar mechanism and orientation has been proposed for electrochemical enhanced adsorption of aniline on activated carbon fibers (Han et al., 2006), with electrosorption taking place through the aromatic ring approaching the charged carbon surface. Attractive electrostatic interactions between the anionic form of bentazone (predominant in the electrolytic solution) and the positively charged carbon surface (induced by the anodic polarization) might also occur to some extent. This would also lead to a faster uptake.

One should bear in mind that a slight oxidation of the carbon cloth might occur upon anodic polarization (due to oxygen evolution), which could result in a partial collapse of the porous network. Nevertheless, the mild experimental conditions of the electrochemical treatment (current up to $+5 \mathrm{~mA}$ during 3 hours) prevented a large deterioration of the porous texture of the carbon cloth (Table 1). Also, based on the mechanism proposed for adsorption under OC conditions, a modification of surface functionality should have a negative effect on bentazone uptake (Ania and Béguin, 2007) due to the occurrence of negative charges on the cloth, arising from the created oxygen groups. Since it is not the case, two factors should be considered. First, although oxygen evolution produces acidic groups 
(confirmed by decrease in $\mathrm{pH}$ Pzc), these may be created either in small amount or surface groups. On the other hand, the simultaneous liberation of $\mathrm{H}^{+}$during anodic polarization provokes the cancellation of the negative charges arising form the dissociation of the acidic groups, so that the negative effect due to repulsive electrostatic interactions is minimized.

\subsection{Desorption of bentazone under cathodic polarization}

When a cathodic (negative) polarization is applied to an exhausted sample, the reversible desorption of bentazone occurs (Figure 3). This is an interesting finding from the point of view of the adsorbent regeneration. The UV absorption spectra of the solution recorded in-situ upon cathodic polarization show that the amount of bentazone in solution increased with time, indicating that it is being desorbed from the activated carbon (Figure 4). This also probes that the bentazone molecule is weakly adsorbed (no strong or irreversible interactions occur between the adsorbate and the carbon substrate) on the carbon cloth and that it does not undergo decomposition and/or polymerization. Support for the structural integrity of bentazone under cathodic polarization is the absence of a line shift in the UV spectra (recorded in-situ), although the electrode potential reached during the electrodesorption experiments is very low (i.e., $-1700 \mathrm{mV}$ vs $\mathrm{Hg} / \mathrm{Hg}_{2} \mathrm{SO}_{4}$ ).

The reversibility of the process upon reversal of polarization is in good agreement with the proposed mechanism for bentazone adsorption under both open circuit and anodic polarization (Ania and Béguin, 2007). As aforementioned, desorption cannot be attributed to changes in porosity, since the latter is not altered after applying a negative polarization, therefore it should be attributed to other factors. First, desorption might be due to the fact that cathodic polarization generates $\mathrm{OH}^{-}$at the working electrode, where the adsorbed molecules ionize to their anionic form. Consequently, electrostatic repulsive interactions arise due to the negative charges of the cloth surface and the anionic form of the bentazone molecules. On the other hand, negative charges on the carbon cloth might affect the charge distribution of bentazone molecules, inducing repulsive intermolecular forces at the 
interface between the adsorbed bentazone molecules in the flat orientation, thus promoting desorption. The substitution of bentazone molecules by water molecules on the adsorption sites might facilitate the desorption step.

Desorption of bentazone was also confirmed by evaluating the porosity of the regenerated sample $A X$ reg - after cathodic treatment of $A X$ sat during three hours (Table 1). Compared to $A X$ sat (carbon cloth after bentazone adsorption), the BET surface area and total pore volume significantly increased after cathodic regeneration. However, the values are slightly lower than those in the as-received carbon $A X$, particularly the micropore volume, suggesting that desorption is almost quantitative after 3 hours. The decrease is more remarkable in the microporosity, (evaluated by $\mathrm{N}_{2}$ and $\mathrm{CO}_{2}$ adsorption) confirming the premise that adsorption takes place preferentially in the narrow micropores of the carbon cloth. Although the results presented above are new and interesting, more investigations are needed to elucidate the exact mechanism of electrochemical desorption of this herbicide. Moreover, further studies are ongoing to evaluate the feasibility of the regeneration process (i.e., regeneration efficiency) over several cycles.

\section{Conclusions}

Electrochemical techniques were investigated for the adsorption/desorption of a common herbicide in aqueous solution, by means of an activated carbon cloth electrode. Applying anodic polarization to the carbon cloth enhances the adsorption rate of bentazone. It seems that local $\mathrm{pH}$ changes occurring in the vicinity of the working carbon electrode as a consequence of polarization are the main factor which controls the electrosorption of bentazone through ionization of the adsorbate and surface charging of the adsorbent.

Bentazone is likely trapped via two mechanisms: i) $\pi-\pi$ dispersive interactions with the aromatic ring approaching to the carbon surface and ii) electrostatic interactions between the adsorbate and positive 
charges on the carbon surface. The main difference as a result of bentazone adsorption is a decrease of the micropore volume, underlining the important role of the narrow micropores in bentazone uptake. A similar trend was observed for the adsorption in open circuit conditions.

Reversal of the polarization (i.e., cathodic) results in the desorption of the retained adsorbate. Since no structural changes are produced in the carbon cloth upon polarization, this behavior is attributed to the pH increase and/or to the charges created on the carbon electrode.

\section{Acknowledgements}

The authors thank Actitex, France, for kindly supplying the activated carbon cloth. COA thanks the CSIC I3P Program, co-financed by the European Social Fund, for a postdoctoral contract. Dr. Khomenko is also acknowledged for fruitful discussions.

\section{Nomenclature}

$\begin{array}{ll}\text { C } & \text { solution concentration }\left(\mathrm{mg} \mathrm{L}^{-1}\right) \\ \mathrm{C}_{0} & \text { initial solution concentration }\left(\mathrm{mg} \mathrm{L}^{-1}\right) \\ \text { DFT } & \text { density functional theory } \\ \text { DR } & \text { Dubinin-Radushkevich method } \\ \text { E } & \text { equilibrium reduction potential (Volts) } \\ \text { I } & \text { applied current (mA) } \\ K_{\text {ads }} & \left.\text { adsorption rate constant (min }{ }^{-1}\right) \\ \text { NHE } & \text { Normal Hydrogen Electrode } \\ p & \text { Pressure } \\ p_{0} & \text { Saturation pressure }\end{array}$




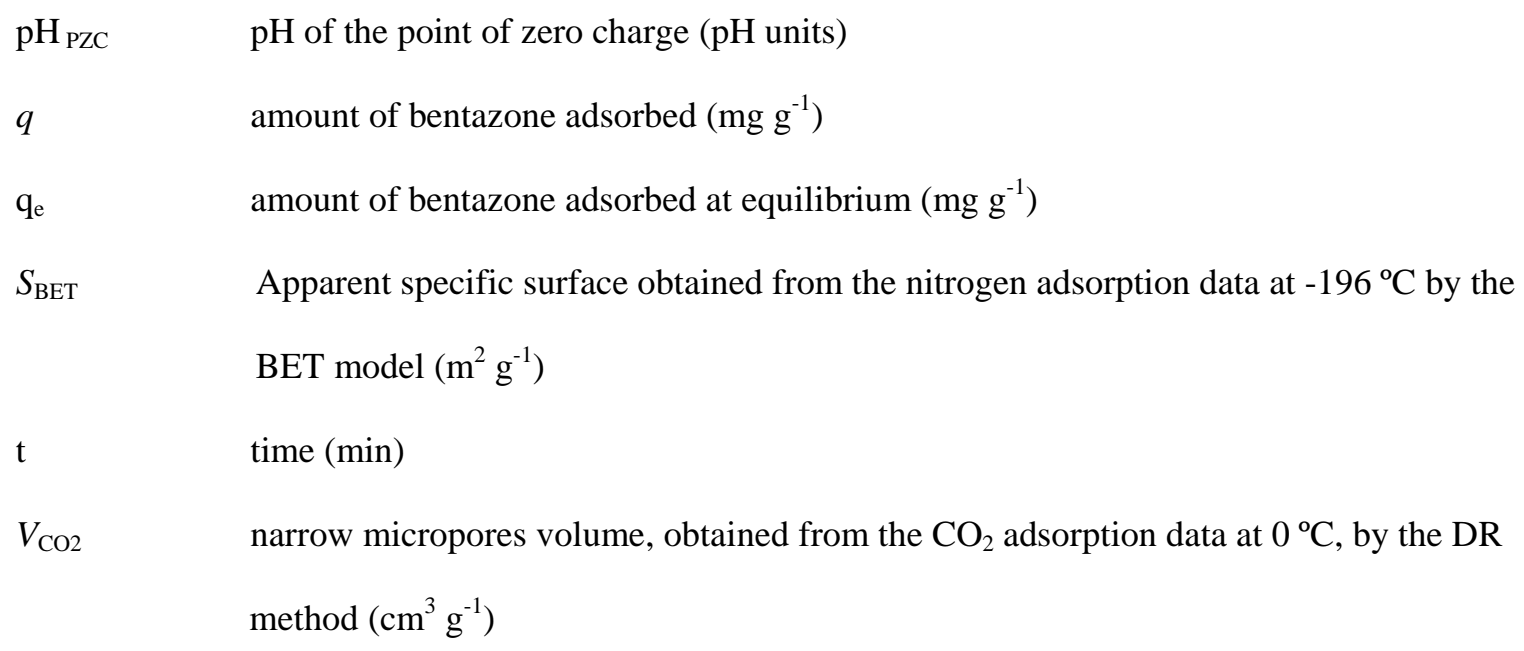

Vmeso Mesopores volume, obtained from the nitrogen adsorption data at $-196{ }^{\circ} \mathrm{C}$, by the DFT method $\left(\mathrm{cm}^{3} \mathrm{~g}^{-1}\right)$

Vmicro Micropores volume, obtained from the nitrogen adsorption data at $-196{ }^{\circ} \mathrm{C}$, by the DFT method $\left(\mathrm{cm}^{3} \mathrm{~g}^{-1}\right)$

$\mathrm{V}_{\text {TотAL }} \quad$ total pore obtained from the nitrogen adsorption data at $-196^{\circ} \mathrm{C}$, and evaluated at $\mathrm{p} / \mathrm{po} \sim 0.95\left(\mathrm{~cm}^{3} \mathrm{~g}^{-1}\right)$ 


\section{REFERENCES}

Afkhami, A. Conway, B.E. "Investigation of Removal of Cr(VI), Mo(VI), W(VI), V(IV), and V(V) Oxy-ions from Industrial Waste-Waters by Adsorption and Electrosorption at High-Area Carbon cloth”. J. Colloid Interf. Sci., 251, 248-255 (2002).

Alfarra, A. Frackowiak, E. Béguin, F. "Mechanism of lithium electrosorpion by activated carbons". Electrochim. Acta, 47, 545-1553 (2002).

Ania, C.O., Béguin, F. "Mechanism of adsorption and electrosorption of bentazone on activated carbon cloth in aqueous solutions”. Wat. Res. accepted (2007a).

Ayranci, E. Conway, B.E. "Removal of phenol, phenoxide and chlorophenols from waste-waters by adsorption and electrosorption at high-area carbon felt electrodes”. J. Electroanal. Chem., 513, 100-110 (2001).

Ayranci, E. Hoda N. "Adsorption of bentazone and propanil from aqueous solutions at the high area activated carbon cloth”. Chemosphere, 57, 755-762 (2004).

Bandosz, T.J. in Activated carbon surfaces for environmental remediation, in the series Interface Science and Technology; Elsevier Ed., New York, 2006.

Boivin, A. Cherrier, R. Schiavon, M. “A comparison of five pesticides adsorption and desorption processes in thirteen contrasting field soils”, Chemosphere, 61, 668-676 (2005).

Brown, N.W., Roberts, E.P.L. Garforth, A.A., Dryfe, R.A.W. "Electrochemical regeneration of a carbon-based adsorbent loaded with crystal violet dye”, Electrochim. Acta, 49, 3269-3281 (2004).

Damaskin, B.B., Petri, O.A., Batrakov, V.V. in Adsorption of Organic Compounds at Electrodes, Plenum Press, New York, 1971.

Directive 2000/60/EC. Official Journal of the European Union, L 327, on 22 December 2000.

Dousset, M. Babut, F. Andreux, Schiavon, M. “Alachlor and Bentazone Losses from Subsurface Drainage of Two Soils”. J. Environ. Qual., 33, 294-301 (2004). 
EPA, Pesticides Industry Sales and Usage Report. United States Environmental Protection Agency Office of Prevention, Pesticides, and Toxic Substances (7503C), 733-R-04-001 (2004).

European Communities. Panorama of the European Union. Measuring progress towards a more sustainable Europe. ISBN 92-894-9768-8. Luxembourg: Office for Official Publications of the European Communities, 2005.

Han, Y. Quan, X. Chen, S. Zhao, H. Cui, C. Zhao, Y. "Electrochemically enhanced adsorption of aniline on activated carbon fibers”. Sep. Purif. Technol., 50, 365-372 (2006a).

Han, Y. Quan, X. Chen, S. Zhao, H. Cui, C. Zhao, Y. "Electrochemically enhanced adsorption of phenol on activated carbon fibers in basic aqueous solution”. J. Colloid Interf. Sci., 299, 766-771 (2006b).

Jurewick, J., Frackowiak, E., Beguin, F. “Towards the mechanism of electrochemical hydrogen storage in nanostructured carbon materials”, Appl. Phys. A78, 981-987 (2004).

Kinoshita, K. In Carbon: electrochemical and physicochemical properties. New York: John Wiley \& sons; p. 293 (1988).

Niu J., Conway B.E., "States of orientation of pyridine and 1,4-pyrazine as a function of electrode potential and surface charge at a high-area, porous C-electrode”. J. Electroanal. Chem. 564, 53-63 (2004).

Niu, J. Conway, B.E. "Development of techniques for purification of waste waters: removal of pyridine from aqueous solution by adsorption at high-area C-cloth electrodes using in situ optical spectrometry”. J. Electroanal. Chem., 521, 16-28 (2002a).

Niu, J. Conway, B.E. "Molecular structure factors in adsorptive removal of pyridinium cations, 1,4pyrazine and 1-quinoline at high-area C-cloth electrodes for waste-water remediation”. J. Electroanal. Chem., 529, 84-96 (2002b). 
Niu, J., Conway, B.E. “Adsorptive and electrosorptive removal of aniline and bipyridyls from wastewaters”. J. Electroanal. Chem., 536, 83-92 (2002c).

Niu, J., Conway, B.E. "Adsorption of organics onto an high-area C-cloth electrode from organic solvents and organic solvent/water mixtures”. J. Electroanal. Chem., 546, 59 -72 (2003).

Noh, J.S. Schwarz, J.A. "Estimation of the point of zero charge of simple oxides by mass titration”. J. Colloid Interf. Sci., 130, 157-164 (1989).

Coughlin, R W. and Ezra, F.S. "Role of Surface Acidity in the Adsorption of Organic Pollutants on the Surface of Carbon”, Environm. Sci. Technol., 2, 291-297 (1968).

Ying, T. Y. Yang, K. L. Yiacoumi, S. Tsouris, C. “Electrosorption of Ions from Aqueous Solutions by Nanostructured Carbon Aerogel”. J. Colloid Interface Sci., 250 18-27 (2002).

Zhou, M.H., Lei, L.C. "Electrochemical regeneration of activated carbon loaded with p-nitrophenol in a fluidized electrochemical reactor”. Electrochim. Acta, 51, 4489-4496 (2006). 


\section{CAPTIONS TO THE FIGURES}

\section{Figure 1.}

Series of successive cyclic voltammograms of the carbon cloth material at $2 \mathrm{mV} \mathrm{s}^{-1}$ sweep rate taken to progressively more A) negative and B) positive, cut-off potential.

\section{Figure 2.}

Concentration decay curves for bentazone under open-circuit (OC) and anodic polarization at $+1,+2$, $+5 \mathrm{~mA}$ in a non-buffered solution (0.01 mol. $\mathrm{L}^{-1} \mathrm{Na}_{2} \mathrm{SO}_{4}$ as supporting electrolyte). The initial concentration of pesticide (20 ppm) and the mass of carbon cloth $(11.5 \mathrm{mg})$ were the same in all cases. Symbols represent experimental data and solid lines the fitting to the kinetics model.

\section{Figure 3.}

Bentazone desorption upon cathodic (galvanostatic) polarization on a pre-exhausted carbon cloth electrode, followed by re-adsorption under open circuit (OC) conditions. Mass of carbon cloth: 11.5 mg.

\section{Figure 4.}

Changes in the UV spectra of the solution while cathodic polarization (-5 mA) is being applied.

\section{CAPTIONS TO THE TABLES}

\section{Table 1.}

Textural and chemical characteristics of the pristine carbon cloth $(A X)$, after electrochemical polarization in the absence of bentazone ( $A X$ anod, $A X$ cath), after bentazone exposure ( $A X$ sat), and after several cycles of cathodic regeneration (AX reg).

\section{Table 2.}

First order adsorption kinetics parameters for bentazone on $A X$ in 0.01 mol. $\mathrm{L}^{-1} \mathrm{Na}_{2} \mathrm{SO}_{4}$ under open circuit (OC) conditions and anodic polarization. 
Table 1.

\begin{tabular}{|c|c|c|c|c|c|c|}
\hline Sample & $\begin{array}{l}S_{\text {BET }} \\
{\left[\mathrm{m}^{2} \mathrm{~g}^{-1}\right]}\end{array}$ & $\begin{array}{l}\text { V }_{\text {TOTAL }}{ }^{\mathrm{a}} \\
{\left[\mathrm{cm}^{3} \mathrm{~g}^{-1}\right]}\end{array}$ & $\begin{array}{l}\text { Vmicro }^{6} \\
{\left[\mathrm{~cm}^{3} \mathrm{~g}^{-1}\right]}\end{array}$ & $\begin{array}{l}\text { Vmeso }^{6} \\
{\left[\mathrm{~cm}^{3} \mathrm{~g}^{-1}\right]}\end{array}$ & $\begin{array}{l}\mathrm{VcO}^{\mathrm{c}} \\
{\left[\mathrm{cm}^{3} \mathrm{~g}^{-1}\right]}\end{array}$ & $\mathrm{pH}_{\mathrm{PZC}}$ \\
\hline AX & 1018 & 0.432 & 0.318 & 0.033 & 0.353 & 5.7 \\
\hline AX anod & 938 & 0.423 & 0.294 & 0.056 & 0.311 & 3.2 \\
\hline AX cath & 1076 & 0.457 & 0.321 & 0.034 & 0.340 & 5.5 \\
\hline$A X$ sat & 484 & 0.237 & 0.148 & 0.047 & 0.170 & - \\
\hline AX reg & 1003 & 0.495 & 0.291 & 0.031 & 0.320 & 6.1 \\
\hline
\end{tabular}

s evaluated at $\mathrm{p} / \mathrm{p}_{0}=0.95$ in the $\mathrm{N}_{2}$ adsorption isotherms at $-196^{\circ} \mathrm{C}$

${ }^{b}$ evaluated from the DFT method applied to the $\mathrm{N}_{2}$ adsorption isotherms at $-196^{\circ} \mathrm{C}$

c evaluated from the $\mathrm{DR}$ method applied to the $\mathrm{CO}_{2}$ adsorption isotherms at $0^{\circ} \mathrm{C}$

Table 2.

\begin{tabular}{|c|c|c|c|}
\hline & $\mathrm{q}_{\mathrm{e}}\left[\mathrm{mg} \mathrm{g}^{-1}\right]$ & $\mathrm{K}_{\mathrm{ads}} \times 10^{3}\left[\mathrm{~min}^{-1}\right]$ & $\mathbf{r}^{2}$ \\
\hline OC & 27.36 & 22.54 & 0.9954 \\
\hline$+1 \mathrm{~mA}$ & 28.62 & 28.43 & 0.9970 \\
\hline$+2 \mathrm{~mA}$ & 29.75 & 37.68 & 0.9945 \\
\hline$+5 \mathrm{~mA}$ & 30.47 & 48.18 & 0.9953 \\
\hline
\end{tabular}


Figure 1.
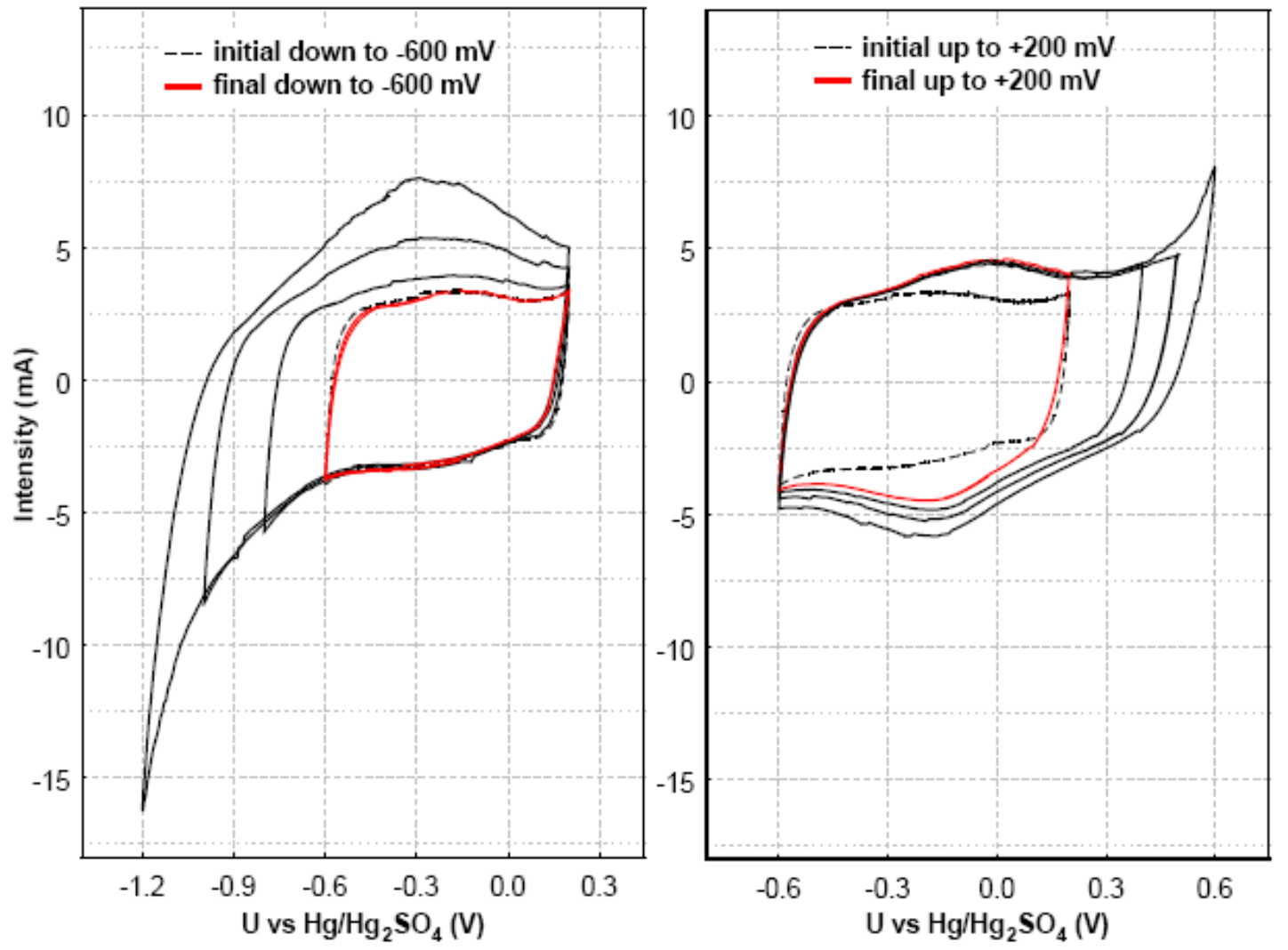
Figure 2

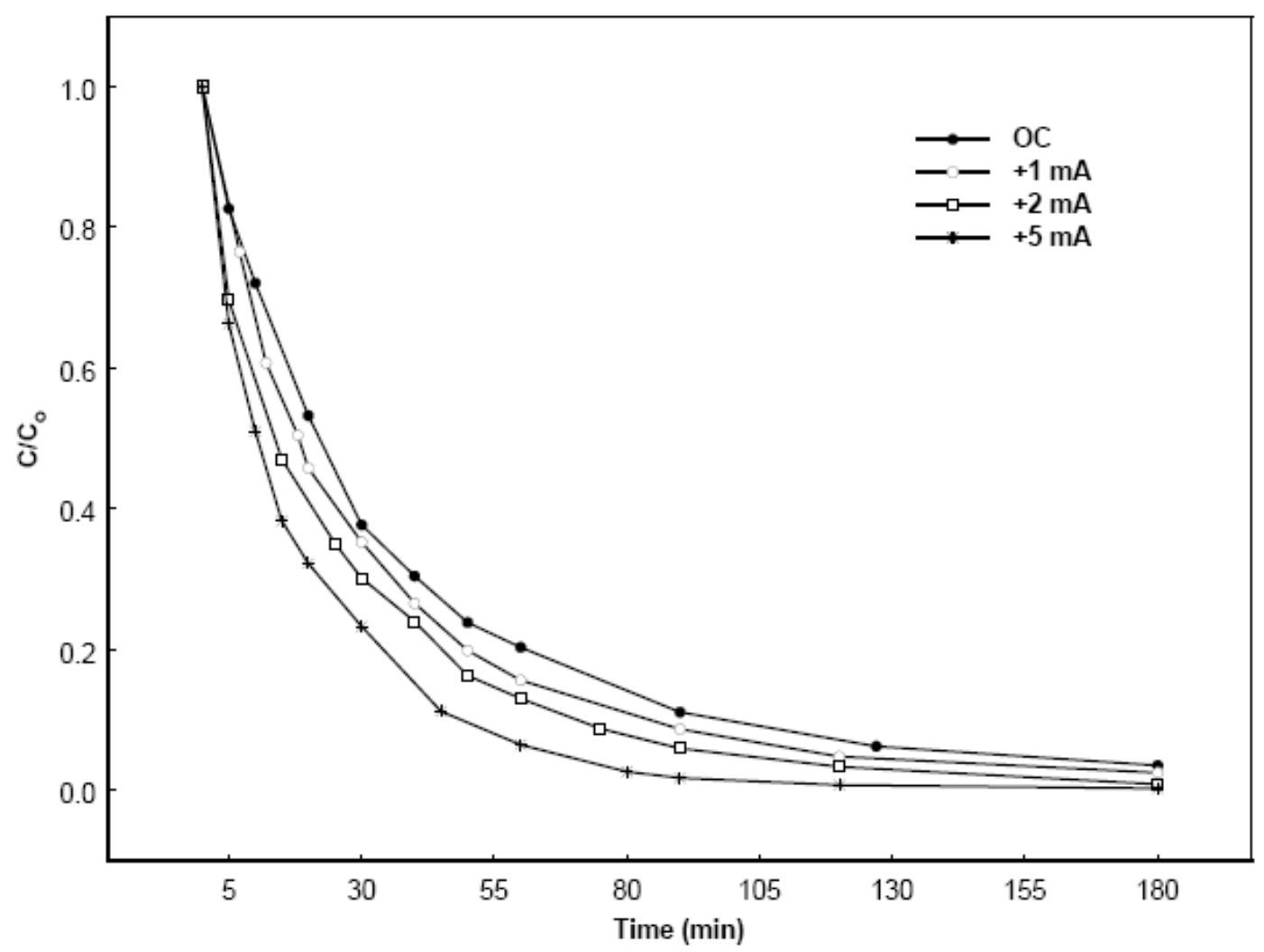


Figure 3

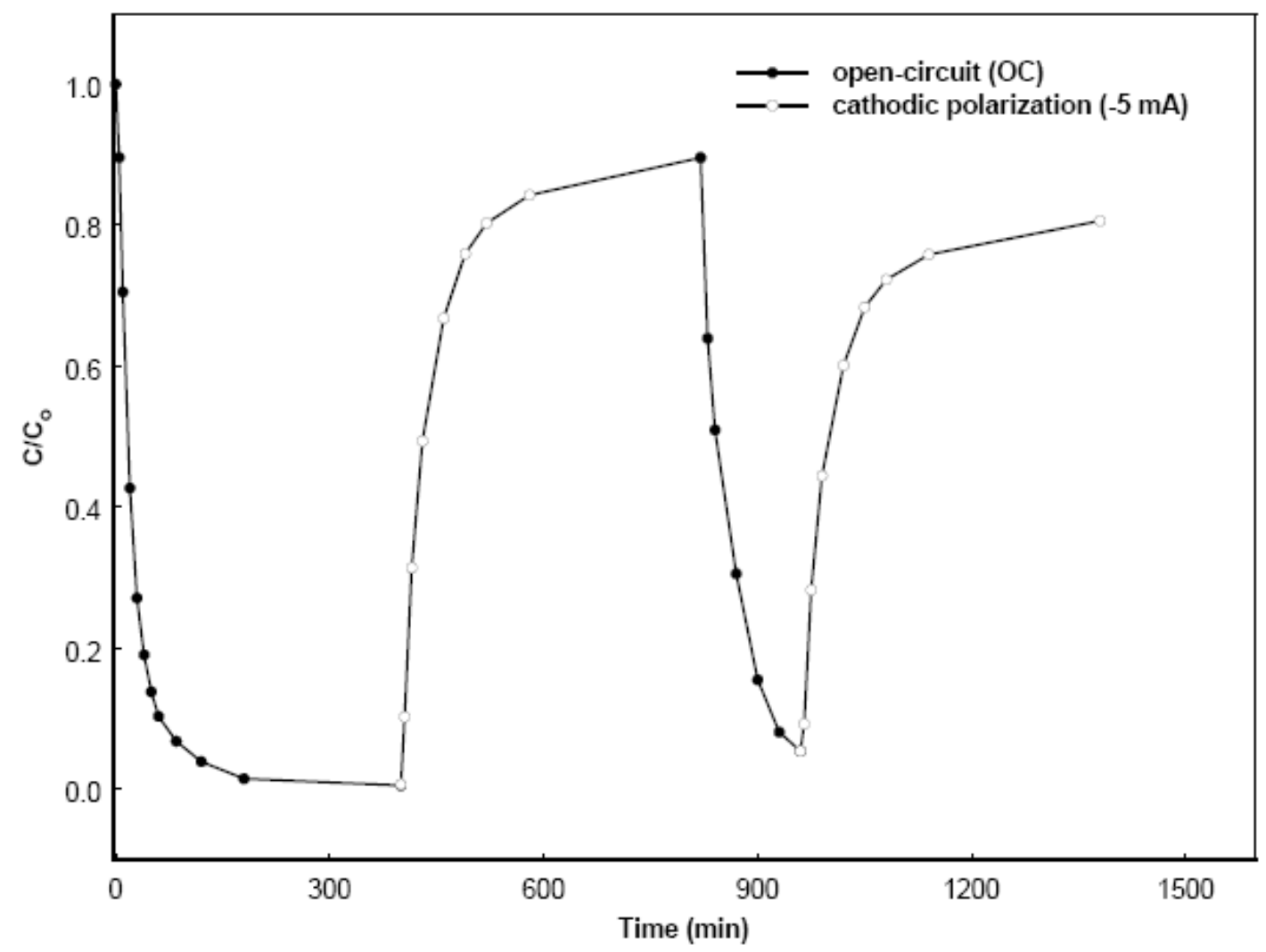


Figure 4.

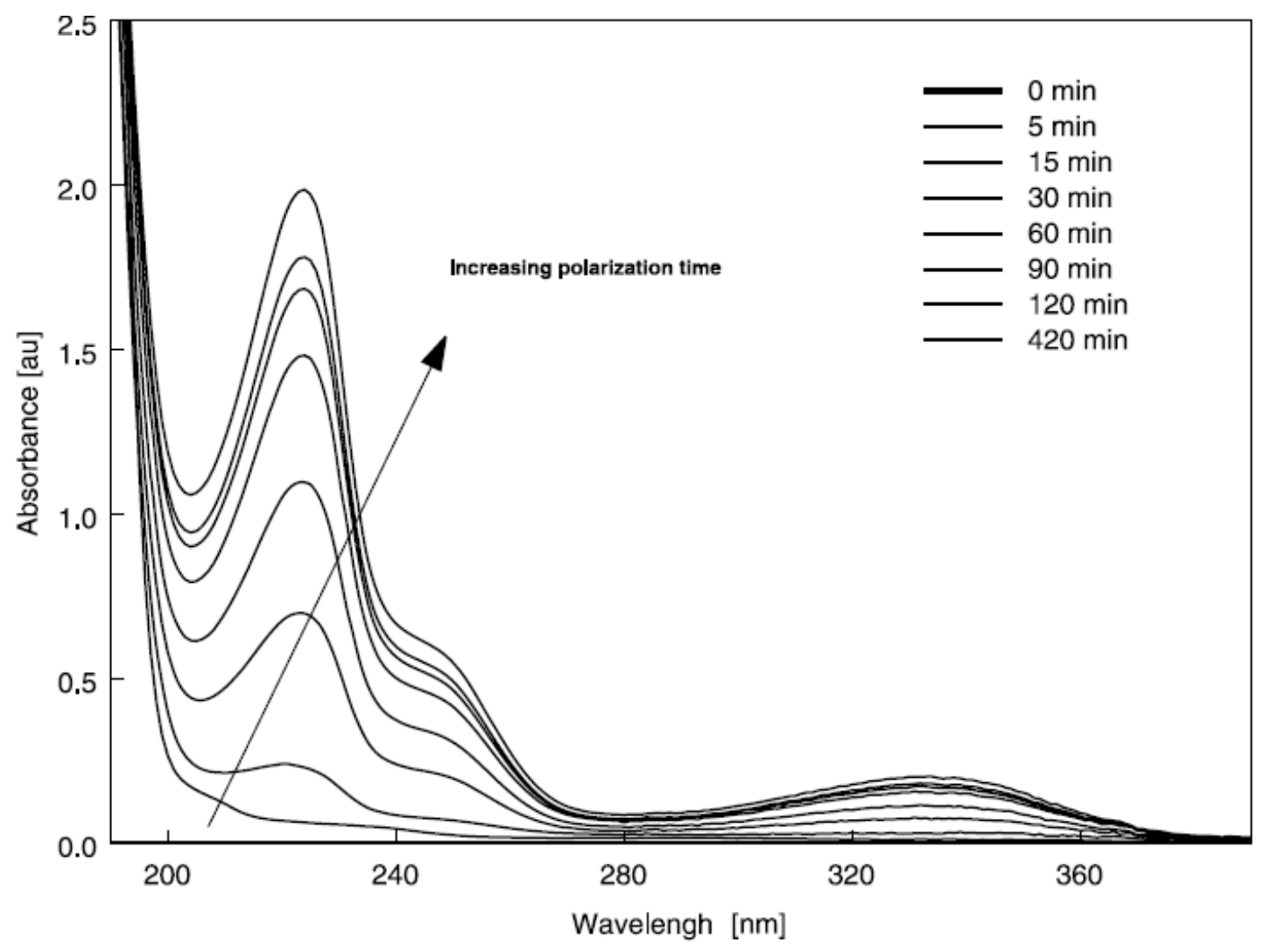

